\title{
Outcome of Adolescents with Acute Lymphoblastic Leukemia Treated by Pediatrics versus Adults Protocols
}

\author{
Abeer Ibrahim, ${ }^{1}$ Amany Ali, ${ }^{2}$ and Mahmoud M. Mohammed ${ }^{2}$ \\ ${ }^{1}$ Department of Medical Oncology and Hematological Malignancy, South Egypt Cancer Institute, Assiut University, \\ El Methaq Street, Assiut, Egypt \\ ${ }^{2}$ Department of Pediatrics Oncology and Hematological Malignancy, South Egypt Cancer Institute, Assiut University, Egypt
}

Correspondence should be addressed to Abeer Ibrahim; abelsayed40@gmail.com

Received 10 August 2014; Revised 22 October 2014; Accepted 29 October 2014; Published 17 November 2014

Academic Editor: Myriam Labopin

Copyright (C) 2014 Abeer Ibrahim et al. This is an open access article distributed under the Creative Commons Attribution License, which permits unrestricted use, distribution, and reproduction in any medium, provided the original work is properly cited.

\begin{abstract}
Objective. Several studies showed better outcome in adolescents and young adults with acute lymphoblastic leukemia (ALL) treated with pediatrics protocols than similarly aged patients treated with adults protocols, while other studies showed similar outcome of both protocols. We conducted this study to compare the outcome of our pediatrics and adults therapeutic protocols in treatment of adolescents ALL. Patients and Methods. We retrospectively reviewed files of 86 consecutive adolescent ALL patients aged 1518 years who attended to outpatients clinic from January 2003 to January 2010. 32 out of 86 were treated with pediatrics adopted BFM 90 high risk protocol while 54 were treated with adults adopted BFM protocol. We analyzed the effect of different treatment protocols on achieving complete remission (CR), disease-free survival (DFS), and overall survival (OS). Results. The 2 patients groups have almost similar characteristics. The CR was significantly higher in pediatrics protocol $96 \%$ versus $89 \%(P=0.001)$. Despite the fact that the toxicity profiles were higher in pediatrics protocol, they were tolerable. Moreover, the pediatrics protocol resulted in superior outcome in EFS $67 \%$ versus $39 \%(P=0.001)$, DFS $65 \%$ versus $41 \%(P=0.000)$, and OS $67 \%$ versus $45 \%$ $(P=0.000)$. Conclusion. Our study's findings recommend using intensified pediatrics inspired protocol to treat adolescents with acute lymphoblastic leukemia.
\end{abstract}

\section{Introduction}

Acute lymphoblastic leukemia (ALL) remains one of the most challenging adults' hematological malignancies [1]. With respect to therapy, the use of multiagent chemotherapy regimens for the treatment of acute lymphoblastic leukemia (ALL) is considered as a cancer success story in the pediatric setting [2], which have offered patients who once had a dismal prognosis a cure rate that approaches or exceeds $90 \%[3,4]$. For adults, the same magnitude of success has not been realized using similar strategies, and the cure rate of adults ALL is estimated to be between 20 and $40 \%[5,6]$. Adults' patients tend to present with higher risk features at diagnosis, predisposing to chemotherapy resistance and disease relapses after initial achievement of complete remission (CR) [7]. On the other hand, within childhood ALL, older children have shown inferior outcomes, and within adults ALL, younger adults have shown superior outcomes. Retrospective studies focusing on patient's age 15 to 21 years showed that "Adolescents and Young Adults" (AYA) treated with adults ALL protocols have poorer outcomes than similarly aged patients treated with pediatric protocols [8-16]. Five-year event-free survival (EFS) for AYA treated with pediatric regimens ranges from $64 \%$ to $69 \%$ while in adult regimen it ranges from $34 \%$ to $49 \%$ [17-20].

In our country, adolescents aged between 15 and 18 years of age are referred either to pediatrics or to adults departments according to physician who firstly made the diagnoses either pediatrician or internist. This study was conducted to assess the outcome of different protocols applied by 2 different teams, namely, pediatrics and adults oncologists in the same age group (adolescent).

\section{Patients and Methods}

2.1. Study Eligibility. We retrospectively reviewed files of 86 consecutive adolescent ALL patients aged 15-18 years old 
TABLE 1: Adults adopted BFM regimen.

\begin{tabular}{|c|c|c|c|}
\hline \multicolumn{4}{|c|}{ Prephase if (TLC $>2.500$ cells $/ \mathrm{mm}^{3}$ and/or oraganomegaly) } \\
\hline Vincristine & $2 \mathrm{mg}$ & IV & D1 \\
\hline Dexamethasone & $10 \mathrm{mg} / \mathrm{m}^{2}$ & IV & (D1-7) \\
\hline \multicolumn{4}{|l|}{ Phase I induction } \\
\hline Vincristine & $2 \mathrm{mg}$ & IV & $(\mathrm{D} 1,8,15,22)$ \\
\hline Doxorubicin & $45 \mathrm{mg} / \mathrm{m}^{2}$ & IV & $(\mathrm{D} 1,8,15,22)$ \\
\hline L-asparaginase & $5000 \mathrm{u} / \mathrm{m}^{2}$ & $\mathrm{IM}$ & $(\mathrm{D} 15-28)$ \\
\hline Dexamethasone & $10 \mathrm{mg} / \mathrm{m}^{2}$ & IV & $\begin{array}{l}11 \text { days (if patients received prophase } 7 \text { days } \\
\text { so to complete } 4 \text { more days only) }\end{array}$ \\
\hline Methotrexate & $15 \mathrm{mg}$ & IT & D1 \\
\hline \multicolumn{4}{|l|}{ Phase II induction } \\
\hline Cyclophosphamide & $650 \mathrm{mg} / \mathrm{m}^{2}$ & IV & $(\mathrm{D} 1,14,28)$ \\
\hline Cytarabine & $75 \mathrm{mg} / \mathrm{m}^{2}$ & IV & $\begin{array}{l}\text { (D3, 4, 5, } 6 \text { and } 9,10,11,12 \text { and } 16,17,18,19 \\
\text { and } 23,24,25,26)\end{array}$ \\
\hline Methotrexate & $15 \mathrm{mg}$ & IT & Given as 4 weekly (D1, 8, 15, 22) \\
\hline Cranial prophylaxis & & & Irradiation (24 Gy) \\
\hline \multicolumn{4}{|l|}{ Phase I consolidation } \\
\hline Vincristine & $2 \mathrm{mg}$ & IV & $(\mathrm{D} 1,8,15,22)$ \\
\hline Doxorubicin & $45 \mathrm{mg} / \mathrm{m}^{2}$ & IV & $(\mathrm{D} 1,8,15,22)$ \\
\hline Dexamethasone & $10 \mathrm{mg} / \mathrm{m}^{2}$ & IV & For 11 days \\
\hline \multicolumn{4}{|l|}{ Phase II consolidation } \\
\hline Cyclophosphamide & $650 \mathrm{mg} / \mathrm{m}^{2}$ & IV & $(\mathrm{D} 1,14,28)$ \\
\hline Cytarabine & $75 \mathrm{mg} / \mathrm{m}^{2}$ & IV & $\begin{array}{l}(\mathrm{D} 3,4,5,6 \text { and } 9,10,11,12 \text { and } 16,17,18,19 \\
\text { and } 23,24,25,26)\end{array}$ \\
\hline Methotrexate & $15 \mathrm{mg}$ & IT & 4 weekly (D1, 8, 15, 22) \\
\hline \multicolumn{4}{|c|}{ Maintenance will be given for two years } \\
\hline 6-Mercaptopurine & $75 \mathrm{mg} / \mathrm{m}^{2}$ & $\mathrm{PO}$ & Daily PO \\
\hline Methotrexate & $20 \mathrm{mg} / \mathrm{m}^{2}$ & IV & Once weekly \\
\hline Triple IT cytarabine 40 & & & Every 2 months till the end of maintenance \\
\hline
\end{tabular}

D: Day, Gy: Gray, IT: intrathecal, MTX: Methotrexate, PO: per oral, TLC: total leucocytes count.

attended to outpatients clinic of pediatrics and adults medical oncology and hematological malignancy departments, South Egypt Cancer institute and pediatric oncology department in Sohag Cancer center, Egypt, from January 2003 to January 2010. We divided them into 2 groups according to their different treatment protocols. Group 1 (pediatrics protocol group) included patients treated with the adopted regimen from pediatric BFM90 high risk protocol (BFM90 HR). Since all the patients were above the age of 10 , they were all considered as high risk patients (Table 1).

Group 2 (adults protocol group) included patients treated with the adopted regimen from adults BFM protocol (BFM) (Table 2 ). The 2 protocols were adopted from original protocols by replacing the Daunorubicin (which is not available in our country) with another form of anthracycline. Epirubicin was used in pediatrics protocol whereas Doxorubicin was used in adults' protocol. Also in pediatrics protocol they changed the high dose Methotrexate from $5 \mathrm{mg} / \mathrm{m}^{2}$ to $3 \mathrm{~g} / \mathrm{m}^{2}$ because they found our pediatrics patients cannot tolerate the original dose. All patients enrolled in the study had complete morphological and immunophenotypical data. Patients who previously received antileukemic treatment or had uncontrolled or severe cardiovascular, hepatic, or renal disease not resulting from ALL and/or severe psychiatric condition were excluded. Also we excluded patients with ALL-L3 (Burkitt'stype ALL), $\mathrm{t}(9: 22)$, and T-cell lymphoblastic lymphoma.

The study was approved by the institutional review board, in accordance with the ethical standards of the responsible committee on human experimentation and with the Helsinki Declaration of 1975.

2.2. Diagnostic Procedure. Morphologic analysis for bone marrow (BM) and peripheral-blood specimens were stained by May-Grünwald-Giemsa. Immunophenotyping was performed by flow cytometry with monoclonal antibodies reactive with B-(CD10, CD19, CD22, sIg, cIg), T-(CD1, CD2, CD3, CD4, CD5, CD7, CD8), and precursor-cell (TdT, HLA$\mathrm{DR}$, and CD34)-associated antigens. Chromosomal analyses using FISH on BM samples were performed at diagnosis for $\mathrm{t}(9: 22)$ only.

2.3. Treatment and Criteria for Response. The treatment regimens are shown in Tables 1 and 2. Patients who achieved $\mathrm{CR}$ received consolidation followed by maintenance for 2 years. Hospitalization, management of infections, and transfusion policies were carried out according to the institutional discretion. 
TABLE 2: Pediatric adopted BFM90 high risk.

\begin{tabular}{|c|c|c|c|}
\hline \multicolumn{4}{|l|}{ Prephase } \\
\hline Prednisolone & $60 \mathrm{mg} / \mathrm{m}^{2}$ & $\mathrm{PO}$ & $(\mathrm{D} 1-7)$ \\
\hline \multicolumn{4}{|l|}{ Induction } \\
\hline Prednisolone & $60 \mathrm{mg} / \mathrm{m}^{2}$ & $\mathrm{PO}$ & (D1-28) \\
\hline Vincristine & $1.5 \mathrm{mg} / \mathrm{m}^{2}$ & IV & $(\mathrm{D} 8,15,22,29)$ \\
\hline Epirubicin & $30 \mathrm{mg} / \mathrm{m}^{2}$ & IV & $(\mathrm{D} 8,15,22,29)$ \\
\hline L-asparaginase & $10.000 \mathrm{u} / \mathrm{m}^{2}$ & $\mathrm{IM}$ & $\begin{array}{c}(\mathrm{D} 19,22,25,28,31,34, \\
37,40)\end{array}$ \\
\hline Triple age adjusted IT & & IT & $(\mathrm{D} 8,15,22,29)$ \\
\hline \multicolumn{4}{|l|}{ High risk I (HRI) } \\
\hline Dexamethasone & $20 \mathrm{mg} / \mathrm{m}^{2}$ & $\mathrm{PO}$ & $(\mathrm{D} 1-5)$ \\
\hline Vincristine & $1.5 \mathrm{mg} / \mathrm{m}^{2}$ & IV & $(\mathrm{D} 1-5)$ \\
\hline 6-Mercaptopurine & $25 \mathrm{mg} / \mathrm{m}^{2}$ & $\mathrm{PO}$ & $(\mathrm{D} 1-5)$ \\
\hline MTX (6 HR infusion) & $3 \mathrm{~g} / \mathrm{m}^{2}$ & IV & (D1) \\
\hline L-asparaginase & $25.000 \mathrm{u} / \mathrm{m}^{2}$ & $\mathrm{IM}$ & (D6) \\
\hline Triple age adjusted IT & & IT & (D1) \\
\hline \multicolumn{4}{|l|}{ High risk II (HRII) } \\
\hline Dexamethasone & $20 \mathrm{mg} / \mathrm{m}^{2}$ & $\mathrm{PO}$ & $(\mathrm{D} 1-5)$ \\
\hline Vincristine & $1.5 \mathrm{mg} / \mathrm{m}^{2}$ & IV & (D1) \\
\hline Ifosfamide & $400 \mathrm{mg} / \mathrm{m}^{2}$ & IV & $(\mathrm{D} 1-5)$ \\
\hline MTX (6 HR infusion) & $3 \mathrm{~g} / \mathrm{m}^{2}$ & IV & (D1) \\
\hline Epirubicin & $50 \mathrm{mg} / \mathrm{m}^{2}$ & IV & (D5) \\
\hline L-asparaginase & $25.000 \mathrm{u} / \mathrm{m}^{2}$ & $\mathrm{IM}$ & (D6) \\
\hline Triple age adjusted IT & & IT & (D1) \\
\hline \multicolumn{4}{|l|}{ High risk III (HRIII) } \\
\hline Dexamethasone & $20 \mathrm{mg} / \mathrm{m}^{2}$ & $\mathrm{PO}$ & $(\mathrm{D} 1-5)$ \\
\hline Vincristine & $5 \mathrm{mg} / \mathrm{m}^{2}$ & IV & (D1) \\
\hline Cytarabine & $1 \mathrm{~g} / \mathrm{m}^{2} / 12 \mathrm{~h}$ & IV & $(\mathrm{D} 2-5)$ \\
\hline Etoposide & $150 \mathrm{mg} / \mathrm{m}^{2}$ & IV & $(\mathrm{D} 2-5)$ \\
\hline L-asparaginase & $25.000 \mathrm{u} / \mathrm{m}^{2}$ & $\mathrm{IM}$ & (D6) \\
\hline Triple age adjusted IT & & IT & (D1) \\
\hline \multicolumn{4}{|c|}{$\begin{array}{l}\text { Total number of HR are } 9 \text { cycles; then if the patient is in CR after the 9th, cranial } \\
\text { prophylaxis }(18 \mathrm{~g}) \text { will be given }\end{array}$} \\
\hline \multicolumn{4}{|l|}{ Maintenance maximum two years with pulses of } \\
\hline Vincristine & $1.5 \mathrm{mg} / \mathrm{m}^{2}$ & IV & (D1) \\
\hline Prednisolone & $40 \mathrm{mg} / \mathrm{m}^{2}$ & $\mathrm{PO}$ & $\begin{array}{l}\text { For } 7 \text { days every two } \\
\text { months }\end{array}$ \\
\hline 6-Mercaptopurine & $25 \mathrm{mg} / \mathrm{m}^{2}$ & $\mathrm{PO}$ & Daily \\
\hline MTX & $20 \mathrm{mg} / \mathrm{m}^{2}$ & $\mathrm{IM}$ & Weekly \\
\hline Triple intrathecal (Methotrexate, Ara-C, hydrocortisone) & & IT & $\begin{array}{c}\text { Every } 2 \text { months till } \\
\text { the end of } \\
\text { maintenance }\end{array}$ \\
\hline
\end{tabular}

D: Day, HR: high risk, Gy: gray, MTX: Methotrexate, PO: per oral.

CR was defined as the absence of clinical manifestations of ALL accompanied with neutrophil count higher than $1.5 \times$ $10^{9} / \mathrm{L}$, platelet count higher than $150 \times 10^{9} / \mathrm{L}$, and hemoglobin levels higher than $100 \mathrm{~g} / \mathrm{L}$ and morphological examination of bone marrow shows less than $5 \%$ of blast cells.

Patients with blast cells in BM greater than $5 \%$ at the end of the induction phase were considered induction failures.
Overall survival was defined as the time from diagnosis until date of death or censoring patients alive at last follow-up date. Disease-free survival (DFS) was defined as survival without relapse or death from the date of first CR or censoring patients alive in continuous complete remission at last follow-up date. Event-free survival (EFS) was defined as time from diagnosis to the date failure of induction course, the date of relapse, 
TABLe 3: Patients' characteristics.

\begin{tabular}{|c|c|c|c|c|c|}
\hline \multirow{2}{*}{ Characteristics } & \multicolumn{2}{|c|}{ Adopted BFM 90 high risk } & \multicolumn{2}{|c|}{ Adopted BFM for adults } & \\
\hline & Number & $\%$ & Number & $\%$ & \\
\hline \multicolumn{6}{|l|}{ Sex } \\
\hline Male & 21 & 66 & 36 & 67 & \multirow{2}{*}{ NS } \\
\hline Female & 11 & 34 & 18 & 33 & \\
\hline \multicolumn{6}{|c|}{ Performance status (ECOG) } \\
\hline $0-1$ & 15 & 47 & 27 & 50 & \multirow{2}{*}{0.049} \\
\hline$>1$ & 17 & 53 & 26 & & \\
\hline Median age & 16 & & 17 & & 0.931 \\
\hline \multicolumn{6}{|l|}{ Phenotype } \\
\hline B lineage & 26 & 81 & 44 & 82 & 0.999 \\
\hline Early pre-B & 4 & 15 & 3 & 7 & 0.001 \\
\hline Common & 4 & 15 & 12 & 27 & 0.032 \\
\hline Pre-B & 18 & 70 & 29 & 66 & 0.047 \\
\hline $\mathrm{T}$ lineage & 6 & 19 & 10 & 18 & 0.919 \\
\hline \multicolumn{6}{|c|}{ Total leucocyte count } \\
\hline \multicolumn{6}{|l|}{ Median } \\
\hline $\mathrm{T}$ lineage $>100$ & 2 & 33 & 4 & 40 & 0.045 \\
\hline B lineage $>50$ & 18 & 56 & 26 & 59 & 0.049 \\
\hline \multicolumn{6}{|l|}{ Serum LDH level } \\
\hline Normal & 7 & 22 & 4 & 6 & 0.920 \\
\hline Elevated & 25 & 78 & 50 & 92 & 0.051 \\
\hline Induction death & 1 & & 3 & & 0.009 \\
\hline $\mathrm{CR}$ & 27 & 96 & 48 & 89 & 0.001 \\
\hline
\end{tabular}

CR: complete remission.

or death or censoring patients alive in continuous complete remission at last follow-up date [9].

\section{Statistical Analysis}

Bivariate tests, Mann-Whitney test, and variance analysis were used to compare quantitative variables when appropriate and the $X^{2}$ test was used to assess differences in proportions. All comparisons were two-tailed.

Actuarial curves for DFS and OS were plotted according to the Kaplan-Meier method [21] and were compared by the log-rank test. The statistically significant variables identified in univariate analysis were included in multivariable analyses.

\section{Results}

4.1. Patient Characteristics. We reviewed retrospectively data of 86 patients who received treatment from January 2003 to January 2010; the characteristics of the patients were summarized in Table 3.

The B lineage was accounted for $81 \%$ in pediatrics protocol group and $82 \%$ in adults protocol group whereas the $\mathrm{T}$ lineage was accounted for $19 \%$ in the pediatrics protocols group and $18 \%$ in the adults one $(P=0.091)$.

The total leucocytes count (TLC) in B lineage ALL was $>50 \times 10^{9}$ cells $/ \mathrm{L}$ in $56 \%$ in pediatrics protocol group, and $59 \%$ in adults protocol group $(P=0.049)$. On the other hand, T lineage ALL showed total TLC count of $>100 \times 10^{9}$ cells $/ \mathrm{L}$ in $30 \%$ in pediatrics protocol group, and 33\% in adults one $(P=0.045)$. No significant difference was remarked between the 2 groups regarding other variables like median age and distribution of sex.

4.2. CR Rates. Our results showed higher percentage of patients who achieved CR in the pediatrics protocol group than the adults' protocol group after first induction (96\% versus $89 \%$ ) (Table 3); only one death was reported during induction in pediatrics protocol group whereas 3 patients died during induction in adults protocol group $(P=0.009)$. No other treatment related deaths were reported in the other phases in both regimens.

Sepsis was the main cause of death in the patient treated with pediatrics protocol and in the 2 patients treated with adults one; however, the third patient in adults protocol group died from CNS hemorrhage.

4.3. Relapse Rate. In pediatrics protocol group, 10 patients (31\%) had relapsed after median followup of 39 months with cumulative incidence of relapse "CIR" (0.401) and standard error "SE" (0.1), 6 patients (60\%) had isolated BM relapse, 2 patients (20\%) had CNS relapse, and 2 patients (22\%) had testicular relapse. Timing of relapse was as follows: 1 patient relapsed during consolidation phases, 1 patient relapsed during the first of year of maintenance, 2 patients relapsed in the second years of maintenance, 3 patients relapsed after one 
TABLE 4: Toxicity profile difference between 2 regimens during induction.

\begin{tabular}{|c|c|c|c|}
\hline Toxicity & aBFM 90-HR (\%) & aBFM standard (\%) & $P$ value \\
\hline \multicolumn{4}{|l|}{ Neutropenia } \\
\hline GI-II & 60 & 70 & 0.049 \\
\hline GIII-IV & 40 & 30 & 0.049 \\
\hline Thrombocytopenia GIV & 40 & 25 & 0.003 \\
\hline Mucositis GIII-GIV & 30 & 20 & 0.005 \\
\hline Thrombotic events & 7 & 6 & 0.010 \\
\hline \multicolumn{4}{|l|}{ Liver impairment } \\
\hline Elevated bilirubin & 37 & 20 & 0.001 \\
\hline Elevated enzyme & 28 & 11 & 0.003 \\
\hline
\end{tabular}

TABLE 5: Survival evaluation according to different protocols.

\begin{tabular}{lccc}
\hline & aBFM $90-\mathrm{HR}(\%)$ & aBFM standard (\%) & $P$ value \\
\hline EFS & 67 & 39 & 0.001 \\
DFS & 65 & 41 & 0.000 \\
OS & 67 & 45 & 0.000 \\
\hline
\end{tabular}

CR: complete remission, EFS: event-free survival, DFS: disease-free survival, OS: overall survival.

year of finishing maintenance, and 3 patients relapsed after 2 years of maintenance.

During the same period of followup for the adults protocol group, 30 patients had relapsed (55\%) with CIR 0.631 and SE 0.06. 24 patients (80\%) had isolated BM relapse, 3 patients (10\%) had CNS relapse, 3 patients $(10 \%)$ had CNS and $\mathrm{BM}$ relapse, and none of the patients had testicular relapse. Timing of relapse was as follows: 4 patients relapsed during the consolidation phases, 5 patients during maintenance, 4 patients relapsed shortly after maintenance, and 7 patients relapsed after one year of maintenance, 5 patients after 2 years of finishing maintenance, and 4 patients after 3 years of finishing maintenance.

4.4. Dose Intensity. In pediatrics protocol group, the Lasparaginase dose was 8 times higher than the one used in adults protocol. The cytarabine dose was 4 times higher than the adults' doses; the Dexamethasone was double the dose used in adults protocol and the vincristine dose is almost the same in the 2 protocols; however the vincristine was included in maintenance phase in the pediatrics protocol but not in the adults one. The Etoposide, Ifosfamide, and high dose of Methotrexate are included in the pediatrics protocol but not in the adults one. The duration of treatment was longer in the pediatrics protocol than it was in the adults one due to the fact that induction and consolidation take about 8 months in pediatrics protocol, while they take 3.5 months in the adults. Also, the duration of admission to hospital was also longer in pediatric protocol and also supportive treatment was more in pediatric regimen.

4.5. Toxicity. The study showed higher incidence grade III and IV neutropenia (Table 4) in pediatrics protocol group which resulted in higher episodes of grade III and IV mucositis; also the frequency of grade III and IV thrombocytopenia was more in pediatrics protocol group. Liver impairment due to L-asparaginase, either in the form of elevated bilirubin levels or in elevated liver enzymes, was significantly higher in pediatrics protocol group. The elevated bilirubin levels occurred in 12 patients (37.5\%) in pediatrics protocol group, and in $11(20.3 \%)$ patients in adults protocol group $(P=$ $0.001)$. The elevated liver enzymes occurred in 9 patients $(28 \%)$ in pediatrics protocol group and in 6 patients $(11 \%)$ in adults protocol group $(P=0.003)$. However, the liver function tests retained normal levels after median 14 days in pediatric protocol group and 9 days in adults protocol group.

Additionally, there was no significant difference in the number of thromboses related to L-asparaginase that occurred in one patient in pediatric protocol $3 \%$ and 2 patients in adults protocol $3.7 \%$ in adults group $(P=0.091)$.

4.6. Survival Outcome. After median 39 months of followup, EFS was significantly higher in patients treated in pediatric protocol group 67\% (95\% CI, 50\%-73\%) versus 39\% (95\% CI, 30\%-55\%) in the adults protocol group $P=0.001$; the estimated 5-year DFS was 65\% (95\% CI, 59\%-70\%) in pediatrics protocol group versus $41 \%$ (95\% CI, 35\%-48\%) in adults protocol group $P=0.000$ (Figure 1). Consequently, OS was higher in pediatric protocol group 67\% (95\% CI, 60\%$72 \%)$ than adults protocol group $45 \%$ (95\% CI, 40\%-51\%) $P=0.000$ (Figure 2) (Table 5).

We carried out subanalysis regarding the $\mathrm{T}$ lineage groups; the DFS and OS in T-ALL were found to be more than double in pediatrics protocol group compared to that in the adults protocol group $61 \%$ versus $25 \%(P=0.001)$ and $65 \%$ versus $26 \%(P=0.001)$, respectively.

\section{Discussion}

Adolescent and young adults AYAs constitute a particular group of patients who find themselves sandwiched between children and adults and who may be referred to either pediatrics or adults oncologists. Several studies comparing the outcome of AYAs on pediatric and adult protocols demonstrated improved survival for AYAs, who were treated by pediatrics protocols; these findings triggered intense interest in the differences with respect to ALL biology and protocol designs in that age group [22-24]. However, because the results are controversial [25], we conducted this study to compare the efficacy and outcome of our institute adopted 


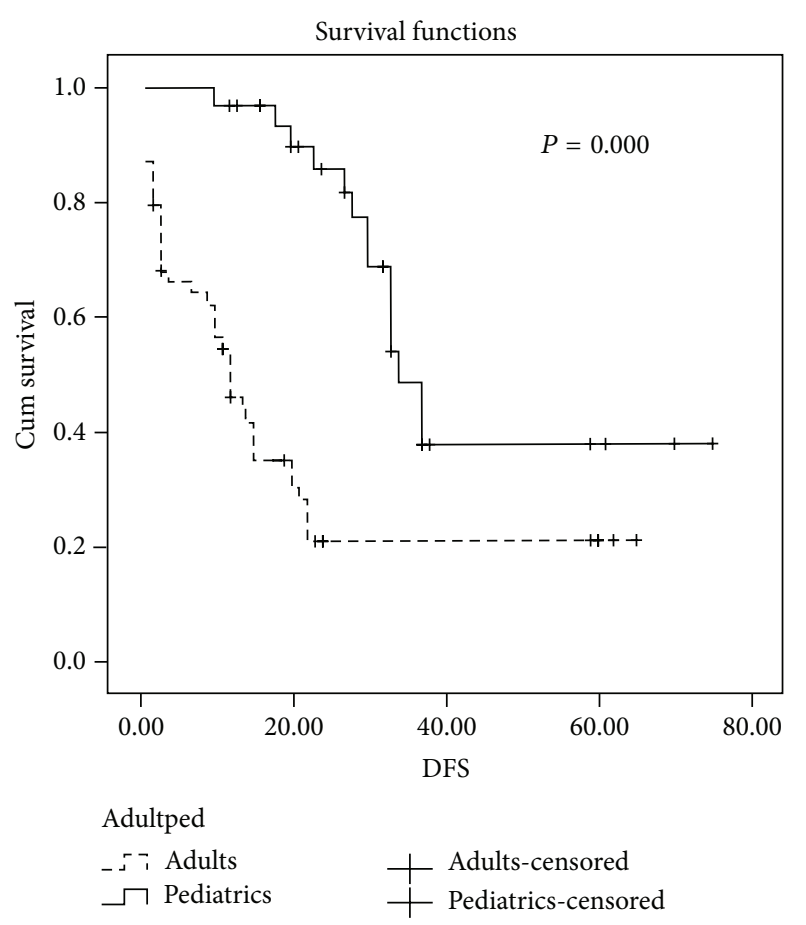

FIGURE 1: Disease-free survival difference between using pediatrics and adults protocols.

pediatrics and adults protocols (adult BFM and pediatric BFM90-HR).

The clinical characteristics between 2 groups were quite similar regarding $\mathrm{B}$ and $\mathrm{T}$ phenotype distribution and the number of patients who had elevated TLC.

Our results showed significant high remission rate 96\% and significant difference in EFS $(P=0.001)$ and DFS $(P=0.000)$ in pediatric protocol group. This difference was attributed mainly to high CR rate and lower relapse rate in the pediatrics group. This could be explained based on the differences in induction and consolidation courses, between the 2 protocols since pediatrics protocol has double doses of L-asparaginase and it was repeated in higher doses in all 9 phases of consolidation in pediatrics protocol. Our results are in line with Dana-Farber Consortium study, which showed that children aged 9 to 18 years may have benefited from higher doses of L-asparaginase especially those with T-ALL despite the increased related toxicity [26]. Moreover, the pediatrics protocol is more intensified regimen as it contains higher doses of cytarabine than the adults' protocol in addition to the high doses of Methotrexate which were not included in adults' protocol. The benefit of this strategy was initially proposed by the Berlin-Frankfurt-Munster study group and then it was established by several other studies [2729]. We noted that the incidence of chemotherapy-related toxicity showed higher significant difference in pediatrics protocol due to the use of more intensified regimen especially in the number of episodes of neutropenia, mucositis, and liver impairment. However, these episodes were reversible and they did not increase the number of deaths. The significant difference which we found in the toxicity profile might contradict the results of similar study conducted by Huguet

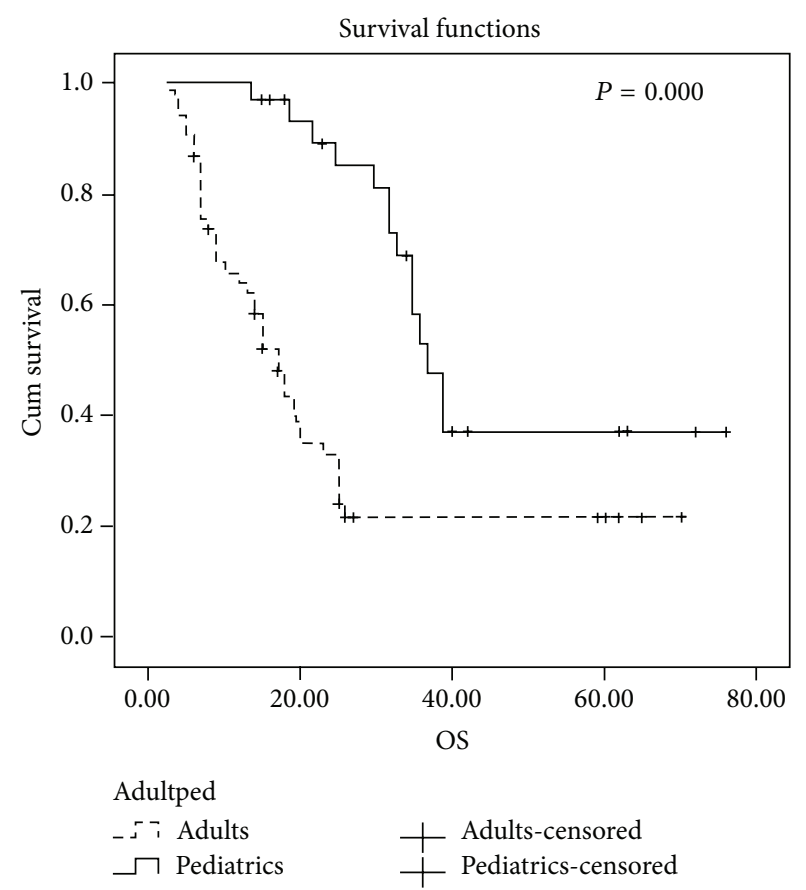

FIgURE 2: Overall survival difference between using pediatrics and adults' protocols.

et al. [20] because they used more intensified regimen in adults than the regimen we used, which resulted in similar toxicity profile when compared to their center pediatrics protocol. Moreover, our results disagree with the results from Finland, which showed no significant difference regarding DFS and OS between their pediatrics and adults protocols; we also found that they used more intensified regimen in adults which was very similar to their pediatrics protocol [25].

\section{Conclusion}

We recommend using intensified pediatrics inspired protocol to treat adolescents with acute lymphoblastic leukemia.

\section{Conflict of Interests}

The authors declare that there is no conflict of interests regarding the publication of this paper.

\section{References}

[1] C.-H. Pui, L. L. Robison, and A. T. Look, "Acute lymphoblastic leukaemia," The Lancet, vol. 371, no. 9617, pp. 1030-1043, 2008.

[2] C.-H. Pui, C. G. Mullighan, W. E. Evans, and M. V. Relling, "Pediatric acute lymphoblastic leukemia: where are we going and how do we get there?" Blood, vol. 120, no. 6, pp. 1165-1174, 2012.

[3] E. J. Freireich, "The history of leukemia therapy—a personal journey," Clinical Lymphoma Myeloma and Leukemia, vol. 12, no. 6, pp. 386-392, 2012.

[4] C.-H. Pui, D. Campana, D. Pei et al., "Treating childhood acute lymphoblastic leukemia without cranial irradiation," The New 
England Journal of Medicine, vol. 360, no. 26, pp. 2730-2741, 2009.

[5] J. I. Sive, G. Buck, A. Fielding et al., "Outcomes in older adults with acute lymphoblastic leukaemia (ALL): results from the international MRC UKALL XII/ECOG2993 trial," British Journal of Haematology, vol. 157, no. 4, pp. 463-471, 2012.

[6] D. A. Thomas, S. O’Brien, S. Faderl et al., "Chemoimmunotherapy with a modified hyper-CVAD and rituximab regimen improves outcome in de novo Philadelphia chromosomenegative precursor B-lineage acute lymphoblastic leukemia," Journal of Clinical Oncology, vol. 28, no. 24, pp. 3880-3889, 2010.

[7] C.-H. Pui and W. E. Evans, "Treatment of acute lymphoblastic leukemia," The New England Journal of Medicine, vol. 354, no. 2, pp. 166-178, 2006.

[8] W. Stock, H. Satjer, R. K. Dodge, C. D. Bloomfield, R. A. Larson, and J. Nachman, "Outcome of adolescents and young adults with ALL: a comparison of Children's Cancer Group (CCG) and Cancer and Leukemia Group B (CALGB) regimens," Blood, vol. 96, abstract 476, 2000.

[9] N. Boissel, M.-F. Auclerc, V. Lhéritier et al., "Should adolescents with acute lymphoblastic leukemia be treated as old children or young adults? Comparison of the French FRALLE-93 and LALA-94 trials," Journal of Clinical Oncology, vol. 21, no. 5, pp. 774-780, 2003.

[10] J. M. de Bont, B. van der Holt, A. W. Dekker, A. van der Does-van den Berg, R. Sonneveld, and R. Pieters, "Significant difference in outcome for adolescents with acute lymphoblastic leukemia treated on pediatric vs adult protocols in the Netherlands," Leukemia, vol. 18, no. 12, pp. 2032-2035, 2004.

[11] R. Ramanujachar, S. Richards, I. Hann, and D. Webb, "Adolescents with acute lymphoblastic leukaemia: emerging from the shadow of paediatric and adult treatment protocols," Pediatric Blood and Cancer, vol. 47, no. 6, pp. 748-756, 2006.

[12] R. Ramanujachar, S. Richards, I. Hann et al., "Adolescents with acute lymphoblastic leukaemia: outcome on UK National Paediatric (ALL97) and adult (UKALLXII/E2993) trials," Pediatric Blood \& Cancer, vol. 48, no. 3, pp. 254-261, 2007.

[13] H. Schrøder, M. Kjeldahl, A. M. Boesen et al., "Acute lymphoblastic leukemia in adolescents between10 and 19 years of age in Denmark," Danish Medical Bulletin, vol. 53, no. 1, pp. 7679, 2006.

[14] A. M. Testi, M. G. Valsecchi, V. Conter et al., "Difference in outcome of adolescents with acute lymphoblastic leukemia (ALL) enrolled in pediatric (AIEOP) and adult (GIMEMA) protocols," Blood, vol. 104, p. 1954, 2004.

[15] H. Hallböök, G. Gustafsson, B. Smedmyr, S. Söderhäll, and M. Heyman, "Treatment outcome in young adults and children > 10 year of age with acute lymphoblastic leukemia in Sweden: a comparison between a pediatric protocol and an adult protocol," Cancer, vol. 107, no. 7, pp. 1551-1561, 2006.

[16] C. A. Schiffer, "Differences in outcome in adolescents with acute lymphoblastic leukemia: a consequence of better regimens? Better doctors? Both?" Journal of Clinical Oncology, vol. 21, no. 5, pp. 760-761, 2003.

[17] D. J. De Angelo, "The treatment of adolescents and young adults with acute lymphoblastic leukemia," Hematology/the Education Program of the American Society of Hematology, pp. 123-130, 2005.

[18] S. E. Sallan, "Myths and lessons from the adult/pediatric interface in acute lymphoblastic leukemia," Hematology/the Education Program of the American Society of Hematology:
American Society of Hematology, vol. 2006, no. 1, pp. 128-132, 2006.

[19] D. J. DeAngelo, L. B. Silverman, S. Couban et al., "A multicenter phase II study using a dose intensified pediatric regimen in adults with untreated acute lymphoblastic leukaemia," Blood, vol. 108, p. 526a, 2006.

[20] F. Huguet, T. Leguay, E. Raffoux et al., "Pediatric-inspired therapy in adults with philadelphia chromosome-negative acute lymphoblastic leukemia: the GRAALL-2003 study," Journal of Clinical Oncology, vol. 27, no. 6, pp. 911-918, 2009.

[21] E. L. Kaplan and P. Meier, "Nonparametric estimation from incomplete observations," Journal of the American Statistical Association, vol. 53, pp. 457-481, 1958.

[22] W. Stock, M. La, B. Sanford et al., "What determines the outcomes for adolescents and young adults with acute lymphoblastic leukemia treated on cooperative group protocols? A comparison of Children's Cancer Group and Cancer and Leukemia Group B studies," Blood, vol. 112, no. 5, pp. 1646-1654, 2008.

[23] N. Boissel, M.-F. Auclerc, V. Lhéritier et al., "Should adolescents with acute lymphoblastic leukemia be treated as old children or young adults? Comparison of the French FRALLE-93 and LALA-94 trials," Journal of Clinical Oncology, vol. 21, no. 5, pp. 774-780, 2003.

[24] R. Ramanujachar, S. Richards, I. Hann et al., "Adolescents with acute lymphoblastic leukaemia: outcome on UK National Paediatric (ALL97) and adult (UKALLXII/E2993) trials," Pediatric Blood and Cancer, vol. 48, no. 3, pp. 254-261, 2007.

[25] A. Usvasalo, R. Räty, S. Knuutila et al., "Acute lymphoblastic leukemia in adolescents and young adults in Finland," Haematologica, vol. 93, no. 8, pp. 1161-1168, 2008.

[26] L. B. Silverman, R. D. Gelber, V. K. Dalton et al., "Improved outcome for children with acute lymphoblastic leukemia: results of Dana-Farber Consortium Protocol 91-01," Blood, vol. 97, no. 5, pp. 1211-1218, 2001.

[27] H. Riehm, H. Gadner, G. Henze et al., "Results and significance of six randomized trials in four consecutive ALL-BFM studies," Haematology and Blood Transfusion, vol. 33, pp. 439-450, 1990.

[28] J. B. Nachman, H. N. Sather, M. G. Sensel et al., "Augmented post-induction therapy for children with high-risk acute lymphoblastic leukemia and a slow response to initial therapy," The New England Journal of Medicine, vol. 338, no. 23, pp. 1663-1671, 1998.

[29] J.-M. Ribera, A. Oriol, M.-A. Sanz et al., "Comparison of the results of the treatment of adolescents and young adults with standard-risk acute lymphoblastic leukemia with the programa Español de tratamiento en hematología pediatric-based protocol ALL-96," Journal of Clinical Oncology, vol. 26, no. 11, pp. 1843-1849, 2008. 


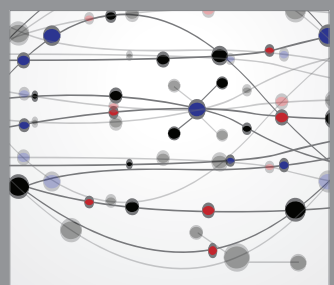

The Scientific World Journal
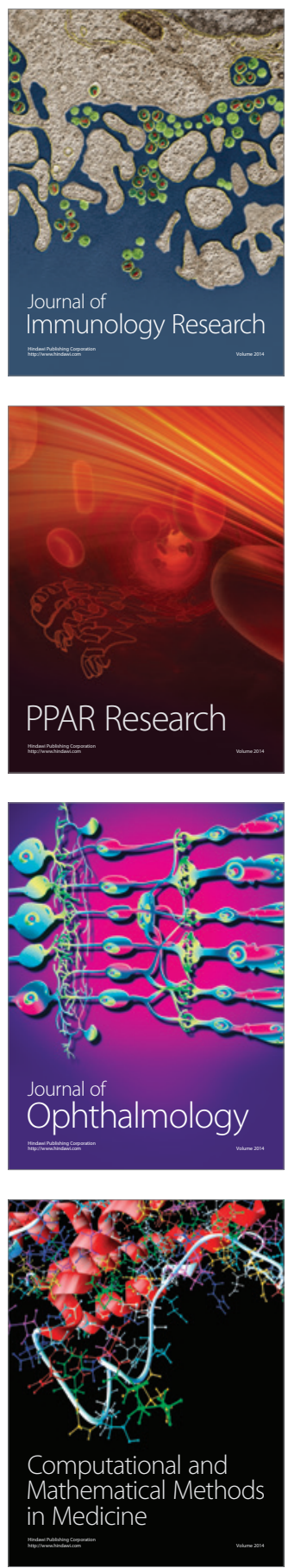

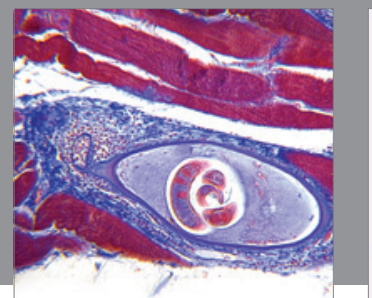

Gastroenterology

Research and Practice
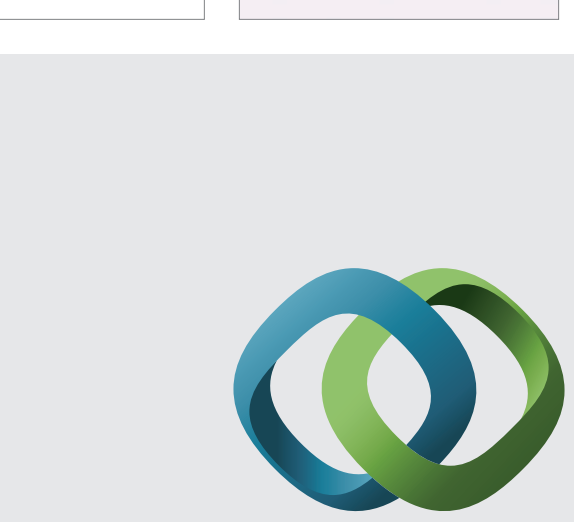

\section{Hindawi}

Submit your manuscripts at

http://www.hindawi.com
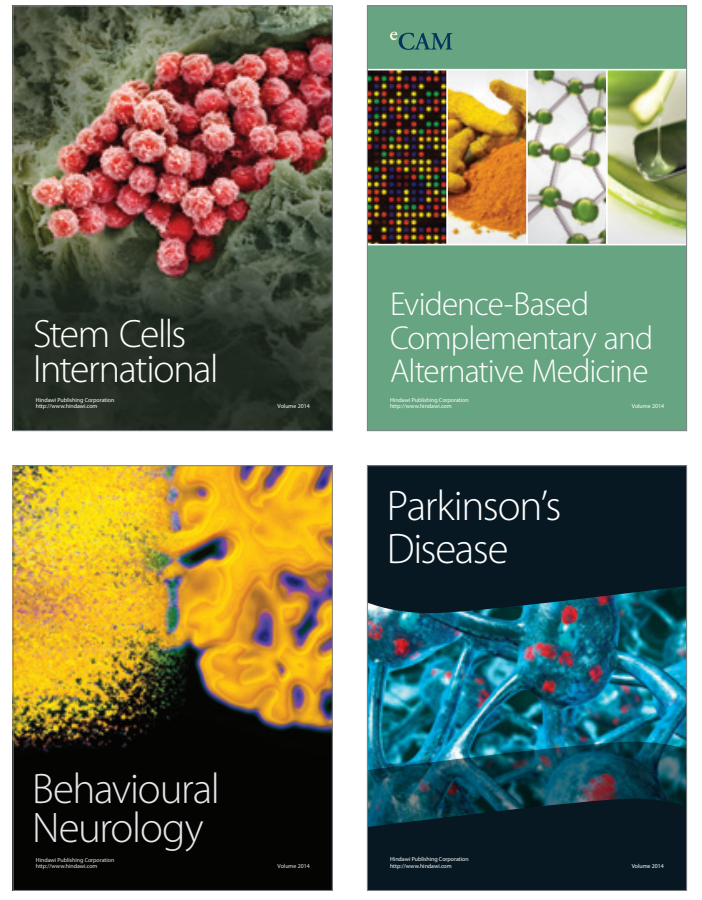
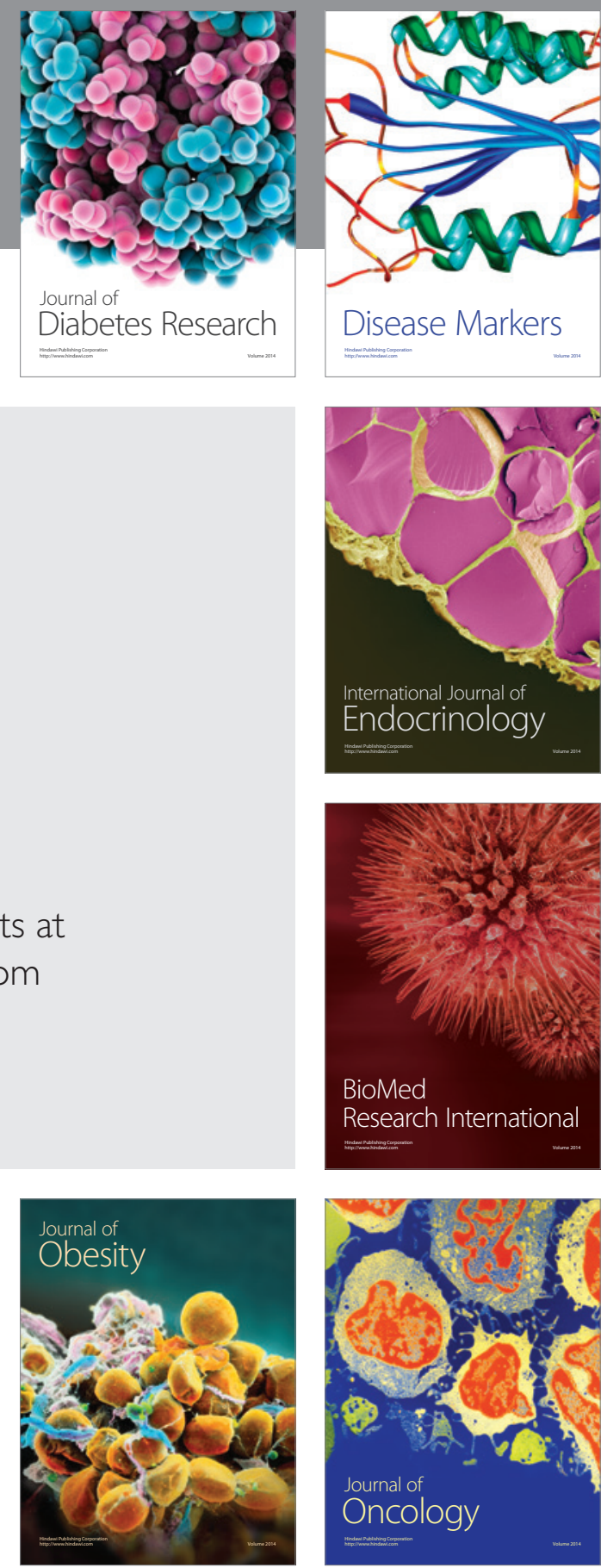

Disease Markers
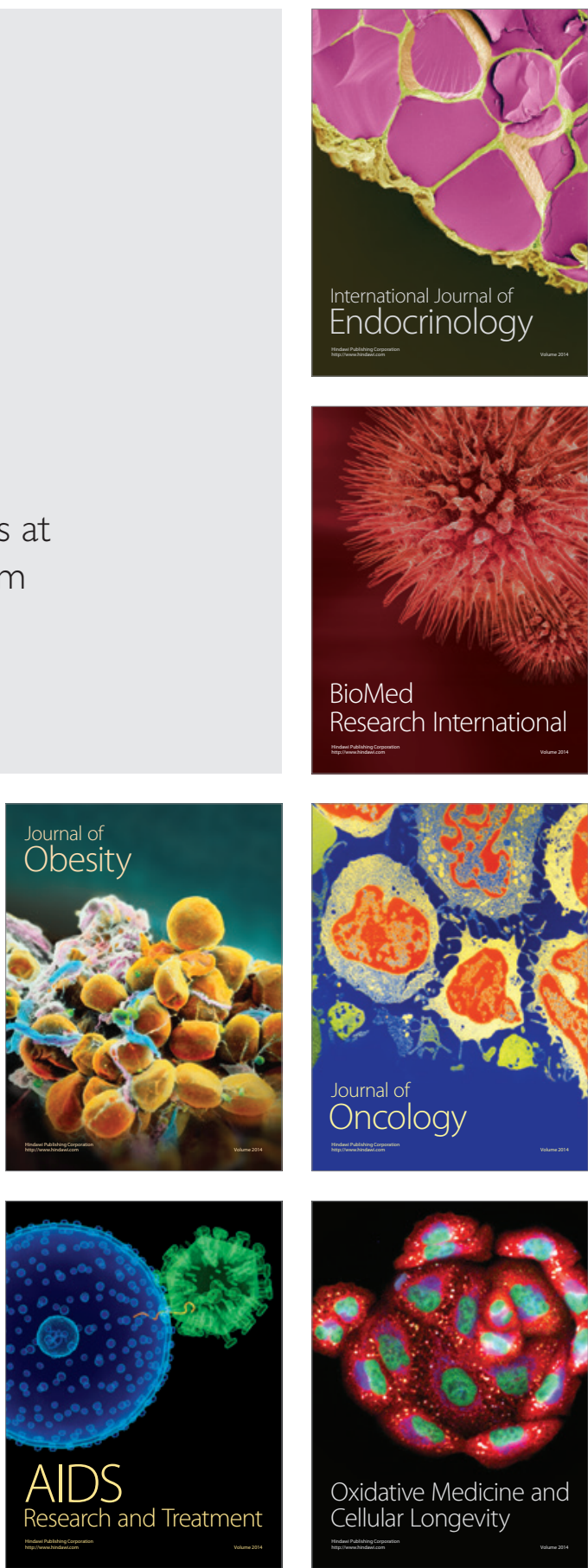